\title{
PERBANDINGAN MODEL GROUP INVESTIGATION DAN NUMBER HEAD TOGETHER: ANALISIS TERHADAP HASIL BELAJAR
}

\author{
Shofiul Hakim ${ }^{1}$, Effendi ${ }^{1 *}$, Widayanti ${ }^{1}$ \\ ${ }^{1}$ Pendidikan Fisika, Sekolah Tinggi Keguruan dan Ilmu Pendidikan Nurul Huda, Sukaraja \\ *corresponding author : effendi@stkipnurulhuda.ac.id
}

Article History:

Received: februari 03, 2020

Revised: maret 13, 2020

Accepted: april 10, 2020

Published: juni 30, 2020

Keywords:

Group

Investigation, Hasil Belajar, Number Head Together

\begin{abstract}
The aim of this study was to analyze the effect of the Model Group Investigation model and the Number Head Together model on learning outcomes. Quasi-experimental method used in this research, the instrument used is multiple choice questions that produce research data. Research data were analyzed using t-test. The results showed that the Group Investigation model and the Number Head Together model could improve learning outcomes. In the result, the class that used the Group Investigation model had a higher score than the class that used the Number Head Together model. For further research, it is necessary to apply a model integrated with interactive multimedia, so that, it will be more interesting and can motivate students in learning.
\end{abstract}

\begin{abstract}
Abstrak: Tujuan penelitian ini untuk menganalisis model Model Group Investigation dan model number head together terhadap hasil belajar. Metode kuasi eksperimental yang digunakan, instrumen berupa soal pilihan ganda yang menjadi data penelitian. Di analisis menggunakan uji t. Hasil penelitian model Group Investigation dan model number head together dapat meningkatkan hasil belajar. Model Group investigation memiliki nilai yang lebih tinggi daripada model number head together. Peneliti selanjutnya perlu adanya penerapan pada model yang terintegrasi dengan multimedia interaktif agar lebih menarik dan memotivasi siswa dalam belajar.
\end{abstract}

\section{PENDAHULUAN}

Pendidikan dijadikan tolok ukur pada sebuah negara (Abdurrahman, Nurulsari, Maulina, \& Ariyani, 2019; Nurcahyono, 2018; Rofiqah, Widayanti, \& Rozaqi, 2020). Pendidikan yang berkualitas menghasilkan negara yang mudah berkembang dan mengikuti perkembangan zaman (Maulana, 2016; Yahya Muhammad, 2018). Kualitas Pendidikan ditentukan oleh beberapa faktor salah satunya pendidik (Elihami, 2016; Vieira \& Tenreiro-Vieira, 2016). Pendidik perlu menerapkan strategi tertentu untuk mendapatkan Pendidikan yang berkualitas. Strategi yang sering dilakukan pendidik pada penerapan model pembelajaran (Awiria, Nadiroh, \& Akbar, 2019; Novianti, Adnyawati, \& Masdarini, 2019).
Model pembelajaran yang di terapkan pendidik diantaranya model problem based learning (Mutakinati, Anwari, \& Yoshisuke, 2018; Pusfarini, 2017; Syazali et al., 2019; Wartono, Diantoro, \& Bartlolona, 2018), project based learning (Aldabbus, 2018; Fini, Awadallah, Parast, \& Abu-Lebdeh, 2018; Widayanti, Yuberti, Irwandani, \& Hamid, 2018), group investigation (Harahap \& Derlina, 2017; Indarti, Mardiyana, \& Pramudya, 2018; Mukti Wijayanti, Sukarmin, \& Wiyono, 2015; Rahmatiah, H, \& Kusairi, 2016; Yuni Tri Astuti, 2017), number head together (Rahmawati, 2017; Satumah, 2017) dan lainnya. Model pembelajaran telah diterapkan pada penelitian dengan berbagai tujuan, diantaranya: mempermudah memahami konsep 
(Anwar et al., 2019; Jatmiko et al., 2018; Putra, Nur Kholifah, Subali, \& Rusilowati, 2018; Winata, Cacik, \& R. W., 2018), meningkatkan kreativitas (Srikoon, Bunterm, Nethanomsak, \& Tang, 2018; Tamba \& Turnip, 2017; Wartono et al., 2018; Yusnaeni, Corebima, Susilo, \& Zubaidah, 2017), meningkatkan motivasi (Korsun, 2017; Rachmatullah, Roshayanti, Shin, Lee, \& Ha, 2018; Rita, 2019), dan meningkatkan hasil belajar (Harahap \& Derlina, 2017; Kristina, Dewi, Ponidi, \& Muzayyana, 2019; Mandailina \& Mahsup, 2018; Nasution, 2020; Satumah, 2017; Surati \& Hurfi, 2019).

Hasil belajar telah ditingkatkan dengan berbagai model diantaranya model Student Team Achievement Divisions (Novianti et al., 2019), model Problem Based Learning (Parasamya \& Wahyuni, 2017), dan Value Clarification Technique (Widayanti, Suwatra, \& Sumantri, 2018). Selain itu model group investigation telah diterapkan dalam meningkatkan prestasi belajar (Rahmatiah et al., 2016), keaktifan dan hasil belajar (Yuni Tri Astuti, 2017) dan model number head together diterapkan untuk meningkatkan penalaran matematis (Rahmawati, 2017) dan hasil belajar (Satumah, 2017).

Kedua model group investigation dan model number head together dapat meningkatkan hasil belajar. Fokus pada penelitian ini menganalisis perbandingan model group investigation dan model number head together dalam meningkatkan hasil belajar.

\section{METODE PENELITIAN}

Penelitian ini menggunakan metode quasi eksperimental. Desain penelitian di tunjukkan pada tabel 1 berikut:
Tabel 1. Desain Penelitian

\begin{tabular}{lll}
\hline Kelompok & Perlakuan & Posttest \\
\hline Eksperimen I & $\mathrm{X}_{1}$ & $\mathrm{Y}_{1}$ \\
Eksperimen II & $\mathrm{X}_{2}$ & $\mathrm{Y}_{2}$ \\
\hline
\end{tabular}

Keterangan:

$\mathrm{X}_{1}$ : Penerapan Model group investigation $\mathrm{X}_{2}$ : Penerapan Model number head together

$\mathrm{Y}_{1}$ : Posttest Model group investigation $\mathrm{Y}_{2}$ : Posttest Model number head together

Penelitian ini menggunakan instrumen tes pilihan ganda. Dianalisis menggunakan uji $\mathrm{z}$ dan beberapa syarat dilakukannya uji t. Diterapkan pada kelas VIII Madrasah Tsanawiyah (MTs) I Sumber Mulyo, Palembang.

\section{HASIL DAN PEMBAHASAN}

Temuan hasil penelitian pada penerapan model kelas eksperimen I dan kelas eksperimen II dilakukan dengan uji$\mathrm{t}$, sebelumnya telah di uji tingkat normalitas dan homogentitas data yang digunakan. Data bersifat normal dan homogen sehingga dilakukan uji-t.

Adapun hasil uji-t ditunjukkan pada Tabel 2 berikut.

Tabel 2. Hasil Uji-t

\begin{tabular}{ccc}
\hline Kelas & $\mathrm{t}_{\text {tabel }}$ & $\mathrm{t}_{\text {hitung }}$ \\
\hline Eksperimen I & \multirow{2}{*}{1,9989} & 2,2771 \\
Eksperimen II & & \\
\hline
\end{tabular}

Hasil uji t pada Tabel 2 menunjukkan adanya pengaruh model Group Investigation dan Number Head Together terhadap hasil belajar. Uraian nilai yang diperoleh pada penelitian ini ditunjukkan pada Tabel 3. 
Tabel 3. Hasil Belajar Kelas Eksperimen I dan Eksperimen II
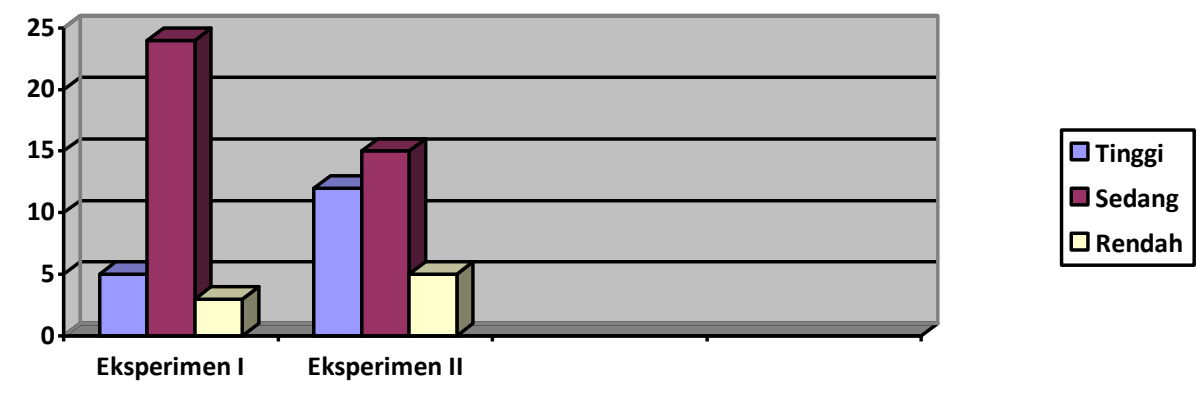

Berdasarkan uraian pada Tabel 3 menunjukkan bahwa eksperimen I menerapkan model group investigation memiliki nilai rata-rata yang lebih rendah dari eksperimen II menerapkan model number head together. Adapun Langkahlangkah yang dilakukan pada penelitian ini ditunjukkan pada Tabel 4 berikut:

Tabel 4. Langkah-langkah Model group investigation dan number head together

\begin{tabular}{|c|c|}
\hline $\begin{array}{l}\text { Model group } \\
\text { investigation }\end{array}$ & $\begin{array}{l}\text { Model number } \\
\text { head together }\end{array}$ \\
\hline 1. Memilih topik & 1. Penomoran \\
\hline 2. Perencanaan & Mengajukan \\
\hline cooperative & Pertanyaan \\
\hline 3. Implementasi & 3. Berfikir Bersama \\
\hline 4. Analisi & 4. Menjawab \\
\hline 5. Presentasi & \\
\hline
\end{tabular}

Materi yang diterapkan pada penelitian adalah materi usaha dan energi. Berdasarkan pada Tabel 4, model Group Investigation memilih topik, kemudian merencanakan pembelajaran yang akan diterapkan di kelas, kemudian melakukan Kerjasama secara berkelompok, mengimplementasikan materi yang diterapkan kemudian menganalisis datanya dan presentasi. Langkah yang diterapkan sangat bagus dan rinci, namun siswa belum terbiasa dengan penerapan model ini. Penelitian ini mendukung penelitian sebelumnya bahwa model GI dapat meningkatkan hasil belajar (Harahap \& Derlina, 2017; Yuni Tri Astuti, 2017).

Model number head together yang peneliti terapkan terdapat empat langkah. Siswa diberikan penomoran pada masingmasing siswa, kemudian bertanya hal yang kurang paham, setelah bertanya siswa Bersama kelompoknya berfikir Bersama dan menjawab dari tujuan utama penerapan materi usaha dan energi. Penelitian ini mendukung peneliti sebelumnya bahwa model number head together (Rahmawati, 2017; Satumah, 2017).

Temuan pada penelitian ini bahwa model number head together jika ditinjau dari hasil belajar lebih tinggi daripada model group investigation. Salah satu kendala yang terjadi karena siswa belum terbiasa dengan penerapan model yang baru diterapkan.

\section{SIMPULAN DAN SARAN}

Model Group Investigation dan model number head together dapat meningkatkan hasil belajar. Model Group investigation memiliki nilai yang lebih tinggi daripada model number head together. Peneliti selanjutnya perlu adanya penerapan pada model yang terintegrasi dengan multimedia interaktif agar lebih menarik dan memotivasi siswa dalam belajar. 


\section{DAFTAR PUSTAKA}

Abdurrahman, A., Nurulsari, N., Maulina, H., \& Ariyani, F. (2019). Design and Validation of Inquiry-based STEM Learning Strategy as a Powerful Alternative Solution to Facilitate Gifted Students Facing 21st Century Challenging To cite this article: Journal for the Education of Gifted Young, 7(March), 33-56. https://doi.org/10.17478/jegys.51330 8

Aldabbus, S. (2018). Project-Based Learning: Implementastion \& Challenges. Internatioanl Journal of Educationm Learning and Development, 6(3), 71-79.

Anwar, C., Saregar, A., Yuberti, Zellia, N., Widayanti, Diani, R., \& Wekke, I. S. (2019). Effect Size Test of Learning Model ARIAS and PBL: Concept Mastery of Temperature and Heat on Senior High School Students. EURASIA Journal of Mathematics, Science and Technology Education, 15(3), 1-9. https://doi.org/https://doi.org/10.293 33/ejmste/103032

Awiria, Nadiroh, \& Akbar, M. (2019). International Journal of Multicultural and Multireligious Understanding The Diversity of the National Culture of Elementary School Students Using the Value Clarification Technique Learning Model. International Journal of Multicultural and Multireligious Understanding, 6(3), 915-923.

Elihami, E. (2016). The Challenge of Religious Education in Indonesia Multiculturalism. Journal of Education and Human Development, 5(4), 211-221. https://doi.org/10.15640/jehd.v5n4a2 0

Fini, E. H., Awadallah, F., Parast, M. M., \& Abu-Lebdeh, T. (2018). The impact of project-based learning on improving student learning outcomes of sustainability concepts in transportation engineering courses. European Journal of Engineering Education, 43(3), 473-488. https://doi.org/10.1080/03043797.20 17.1393045

Harahap, R. A., \& Derlina. (2017). Pembelajaran Kooperatif Tipe Group Investigation (GI) dengan Metode Know-Want-Learn (KWL): Dampak terhadap Hasil Belajar Fluida Dinamis. Jurnal Ilmiah Pendidikan Fisika Al-BiRuNi, 6(2), 149-158. https://doi.org/10.24042/jipfalbiruni. v6i2. 1369

Indarti, D., Mardiyana, \& Pramudya, I. (2018). Group investigation with scientific approach in mathematics learning. In Journal of Physics: Conference Series. IOP Publishing.

Jatmiko, A., Kartina, Y., Irwandani, I., Fakhri, J., Pricilia, A., \& Rahayu, T. (2018). Reading Concept Map-Think Pair Share (Remap-TPS) Learning Model on Cognitive Ability and Scientific Attitude. Tadris: Jurnal Keguruan Dan Ilmu Tarbiyah, 3(2), 183.

https://doi.org/10.24042/tadris.v3i2.3 184

Korsun, I. (2017). The Formation of Learners' Motivation to Study Physics in Terms of Sustainable Development of Education in Ukraine. Journal of Teacher Education for Sustainability, 19(1), 117-128. Retrieved from https://doi.org/10.1515/jtes-20170008

Kristina, M., Dewi, N. A. K., Ponidi, \& Muzayyana, L. (2019). Meningkatkan Hasil Belajar pada Pokok Bahasan Menyimak Teks Cerita Rakyat melalui Pembelajaran Problem Posing Siswa Kelas V SDN 2 Madukoro. Lentera: Jurnal Ilmiah Kependidikan, 12(1), 127-134.

Mandailina, V., \& Mahsup. (2018). Efektivitas Pembelajaran 
Matematika dengan Metode Thinking Aloud Pair Problem Solving (TAPPS) Terhadap Hasil Belajar Siswa Pokok Bahasan Kubus dan Balok Kelas VIII SMP/MTs. Jurnal Teori Dan Aplikasi Matematika, 2(2), 144-147.

Maulana, H. (2016). Pelaksanaan Pendidikan Karakter Di Sekolah Alam. Jurnal Khasanah Ilmu, 7(1), 21-31. https://doi.org/2087-0086

Mukti Wijayanti, F., Sukarmin, \& Wiyono, E. (2015). Penerapan Model Pembelajaran Group Investigation (GI) dengan Menggunakan Media Flash Card untuk Meningkatkan Aktivitas Belajar dan Kemampuan Kognitif Siswa. Jurnal Materi Dan Pembelajaran Fisika ( JMPF ), 5(1), 27-34.

Mutakinati, L., Anwari, I., \& Yoshisuke, K. (2018). Analysis Of Students' Critical Thinking Skill Of Middle School Through Stem Education Project-Based Learning. Jurnal Pendidikan IPA Indonesia, 7(1), 5465.

https://doi.org/10.15294/jpii.v7i1.10 495

Nasution, S. R. A. (2020). Peningkatan Aktivitas dan Hasil Belajar Tematik dengan Strategi Inkuiri pada Tema Lingkungan Di Kelas III SDN 1001004 Sitinjak. Jurnal Education and Development, 8(1), 267-271.

Novianti, N. K. A., Adnyawati, N. D. M. S., \& Masdarini, L. (2019). Pengaruh Model Pembelajaran (STAD) Student Team Achievement Divisions Berbantuan LKS terhadap Hasil Belajar Siswa Kelas X Jasa Boga pada Mata Ajar Keamanan Pangan Di SMK Pariwisata Triatma Jaya Singaraja. Jurnal Bosaparis: Pendidikan Kesejahteraan Keluarga, 10(1), 64-73.

Nurcahyono, O. H. (2018). Pendidikan Multikultural di Indonesia: Analisis
Sinkronis dan Diakronis. Habitus: Jurnal Pendidikan, Sosiologi Dan Antropologi, 2(1), 105-115.

Parasamya, C. E., \& Wahyuni, A. (2017). Upaya Peningkatan Hasil Belajar Fisika Siswa melalui Penerapan Model Pembelajaran Problem Based Learning (PBL). Jurnal Ilmiah Mahasiswa (JIM), 2(1), 42-49.

Pusfarini, P. (2017). Efektivitas Model Problem Based Learning untuk Mereduksi Disparitas Gender dalam Capaian Pembelajaran Sains. Jurnal Ilmiah Pendidikan Fisika Al-Biruni, 6(1), 57. https://doi.org/10.24042/jpifalbiruni. v6i1.909

Putra, F., Nur Kholifah, I. Y., Subali, B., \& Rusilowati, A. (2018). 5ELearning Cycle Strategy: Increasing Conceptual Understanding and Learning Motivation. Jurnal Ilmiah Pendidikan Fisika Al-Biruni, 7(2), 171.

https://doi.org/10.24042/jipfalbiruni. v7i2.2898

Rachmatullah, A., Roshayanti, F., Shin, S., Lee, J., \& Ha, M. (2018). The Secondary-Student Science Learning Motivation in Korea and Indonesia The Science Learning Motivation and the Roles of Educational Level and Gender in its. EURASIA Journal of Mathematics, Science and Technology Education, 14(7), 31233141.

Rahmatiah, R., H, S. K., \& Kusairi, S. (2016). Pengaruh Scaffolding Konseptual dalam Pembelajaran Group Investigation terhadap Prestasi Belajar Fisika Siswa SMA dengan Pengetahuan Awal Berbeda. Jurnal Pendidikan Fisika Dan Teknologi, II(2), 45-54.

Rahmawati, N. K. (2017). Implementasi Teams Games Tournaments dan Number Head Together ditinjau dari Kemampuan Penalaran Matematis. Al-Jabar: Jurnal Pendidikan 
Matematika, 8(2), 121-134.

Rita. (2019). The Effect of Learning Methods and Learning Motivation On Indonesian Learning Outcomes Class X Students of Panca Budi Medan High School. BirLE-Journal, 2(1), 132-137.

Rofiqah, S. A., Widayanti, \& Rozaqi, A. (2020). Thinking Aloud Pair Problem Solving (TAPPS) Method: The Effect of Understanding Physics Concepts and Communication in High Schools in Indonesia. In Young Scholar Symposium on Science Education and Environment 2019 (pp. 1-8). Bandar Lampung: Journal of Physics: Conference Series. https://doi.org/10.1088/17426596/1467/1/012066

Satumah. (2017). Upaya Meningkatkan Hasil Belajar Operasi Hitung Bilangan Bulat melalui Model Number Head Together berbantuan Papan Bilangan. BRILLIANT: Jurnal Riset Dan Konseptual, 2(2), 184189.

Srikoon, S., Bunterm, T., Nethanomsak, T., \& Tang, K. N. (2018). Effect of $5 \mathrm{P}$ model on academic achievement, creative thinking, and research characteristics. Kasetsart Journal of Social Sciences, 39(3), 488-495. https://doi.org/10.1016/j.kjss.2018.0 6.011

Surati, \& Hurfi. (2019). Pengaruh Penggunaan Handout Fisika Berbasis Thinking Aloud Pair Problem Solving terhadap Hasil Belajar Siswa Kelas XI SMA N 1 Ranah Batahan Pasaman Barat. Pillar of Physics Education, 12(1), 9-16.

Syazali, M., Sari, N. R., Sukawati, S., Sari, W. R., Pertiwi, S. D., Putra, A., \& Putra, F. G. (2019). IslamicNuanced Linear Algebra Module with Problem-Based Learning Approach for Linear Equation System Material. Journal of Physics: Conference Series, 1155(1). https://doi.org/10.1088/17426596/1155/1/012097

Tamba, P., \& Turnip, B. M. (2017). The Effect of Project Based Learning Model for Students ' Creative Thinking Skills and Problem Solving. Journal of Research \& Method in Education, 7(5), 67-70. https://doi.org/10.9790/73880705026770

Vieira, R. M., \& Tenreiro-Vieira, C. (2016). Fostering Scientific Literacy and Critical Thinking in Elementary Science Education. International Journal of Science and Mathematics Education, 14(4), 659-680. https://doi.org/10.1007/s10763-0149605-2

Wartono, W., Diantoro, M., \& Bartlolona, J. R. (2018). Influence of Problem Based Learning Learning Model on Student Creative Thinking on Elasticity Topics A Material. Jurnal Pendidikan Fisika Indonesia, 14(1), 32-39.

https://doi.org/10.15294/jpfi.v14i1.1 0654

Widayanti, I. A. V., Suwatra, I. I. W., \& Sumantri, M. (2018). Pengaruh Model Pembelajaran Value Clarification Technique (VCT) terhadap Hasil Belajar PKN Siswa Kelas V di SD Gugus IV Kecamatan Sukasada. E-Journal PGSD Universitas Pendidikan Ganesha, 5(2), 1-10.

Widayanti, Yuberti, Irwandani, \& Hamid, A. (2018). Pengembangan Lembar Kerja Praktikum Percobaan Melde Berbasis Project Based Learning. Jurnal Pendidikan Sains Indonesia, 6(1), 24-31. https://doi.org/10.24815/jpsi.v6i1.10 908

Winata, A., Cacik, S., \& R. W., I. S. (2018). Analisis Kemampuan Awal Literasi Sains Mahasiswa Pada Konsep IPA. Education and Human Development Journal, 1(1), 40-47. 
https://doi.org/10.33086/ehdj.v1i1.29 1

Yahya Muhammad. (2018). Era Industri 4.0: Tantangan Dan Peluang Perkembangan Pendidikan Kejuruan Indonesia. Disampaikan Pada Sidang Terbuka Luar Biasa Senat Universitas Negeri Makassar. Retrieved from http://eprints.unm.ac.id/6456/1/Era Industri 4.0- Tantangan Dan Peluang Perkembangan Pendidikan Kejuruan Indonesia .pdf

Yuni Tri Astuti, A. H. (2017). Implementasi metode brainstorming dalam model group investigation pada mata pelajaran ekonomi untuk meningkatkan keaktifan dan hasil belajar siswa kelas $\mathrm{x}$ ips 3 sman 1 batu. Jurnal Pendidikan Ekonomi, 10(2), 96-103. https://doi.org/https://dx.doi.org/10.1 7977/UM014v10i22017p096 IMPLEMENTASI

Yusnaeni, Corebima, A. D., Susilo, H., \& Zubaidah, S. (2017). Creative Thinking of Low Academic Student Undergoing Search Solve Create and Share Learning Integrated with Metacognitive Strategy. International Journal of Instruction, 10(2), 245-262. 